\title{
External Capsule
}

National Cancer Institute

\section{Source}

National Cancer Institute. External Capsule. NCI Thesaurus. Code C32550.

A thin lamina of white matter comprising long association fibers located between the claustrum and putamen in the brain, and which connects the midportion of the superotemporal region with the midportion of the ventral and lateral aspects of the prefrontal cortex. 